\title{
Expression of a histone H1-like protein is restricted to early Xenopus development
}

\author{
Rosamund C. Smith, Eva Dworkin-Rastl, and Mark B. Dworkin \\ Ernst-Boehringer-Institut, A-1121 Vienna, Austria
}

\begin{abstract}
Genes whose expression is restricted to oogenesis and early development may have important functions in these processes. Northern analysis showed that Xenopus B4 mRNA is expressed in oogenesis and embryogenesis through to the neurula stage. Immunocytochemistry with anti-B4 antibodies showed that B4 protein is only detectable in preneurula stages; it is localized to nuclei and is associated with metaphase chromosomes. Immunoblotting revealed approximately constant levels of B4 protein per embryo for the first 2 days of development. Thus, as the number of nuclei increases during early development, the amount of B4 protein per nucleus is diluted out. Sequencing of two B4 cDNA clones revealed that the predicted B4 translation product is a $29-\mathrm{kD}$ protein with $29 \%$ identity with histone $\mathrm{H1}$, distributed over the entire length of its sequence. The B4 protein also has certain other $\mathrm{H1}$ protein characteristics-a tripartite structure consisting of a mainly hydrophobic central domain flanked by an amino-terminal segment and a long hydrophilic carboxyterminal tail containing a tandemly repeated amino acid motif. However, in contrast to histone H1 mRNA, B4 mRNA has a classic polyadenylation signal, is polyadenylated, and lacks the histone H1 $3^{\prime}$ noncoding consensus sequence involved in RNA processing.
\end{abstract}

[Key Words: Xenopus laevis; development; maternal RNA; histone $\mathrm{H1}$; nuclear protein]

Received May 27, 1988; revised version accepted August 2, 1988.

Zygotic transcription is minimal in the frog Xenopus laevis until approximately $8 \mathrm{hr}$ after fertilization, at the midblastula transition (Bachvarova and Davidson 1966; Newport and Kirschner 1982; Kimelman et al. 1987). During the transcriptionally quiescent period prior to the midblastula transition, major events in pattern formation are known to take place. For example, cytoplasmic movements responsible for the establishment of the dorsal-ventral axis of the future embryo occur during the first cell cycle (Vincent et al. 1986; Vincent and Gerhart 1987), and inductive interactions necessary for mesoderm differentiation begin at the 32- to 64-cell stage (Jones and Woodland 1987). Prior to the midblastula transition, the embryo utilizes mRNAs and proteins synthesized during oogenesis and inherited through the egg.

Genes whose expression is restricted to oogenesis and early development may function in the regulation of the meiotic cell cycle in oocytes, in the rapid cleavage divisions of embryonic cells, or in pattern formation in the early embryo. A number of cDNA clones derived from $\mathrm{mRNAs}$ that are expressed at high levels in the Xenopus oocyte, but have decreased in titer significantly by the gastrula stage and do not accumulate further, have been isolated previously (Dworkin et al. 1985). The strategy followed for the study of the proteins encoded by these RNAs has been to sequence the cDNAs initially so as to identify the open reading frame, and then to compare the putative protein sequences with known proteins in the data banks. Then, using bacterially expressed $\beta$-galactosidase fusion proteins, antibodies raised against the proteins are used to examine both the spatial and temporal expression of the proteins in the oocyte and embryo. Here we describe the characterization of a maternal Xenopus mRNA, B4, whose expression is restricted to oocytes and early embryos. The B4 protein is shown to be nuclear and associated with chromatin in eggs and early embryos and to possess a number of features characteristic of the histone $\mathrm{Hl}$ family of proteins.

\section{Results}

Developmental expression of $B 4 \mathrm{mRNA}$

B4 mRNA is a moderately abundant maternal RNA that is restricted to oogenesis and early development of $X$. laevis. Northern analysis (Fig. 1) showed that the $1.2-\mathrm{kb}$ B4 transcript is present in stage VI oocytes and remains at a constant level through the blastula stage. By the gastrula stage the level of B4 message has started to decline, and by the neurula stage it is barely detectable. The RNA is absent from later-stage embryos (stages 24-26 and stages 37-41) and from the adult tissues tested (muscle and liver). The slight increase in size of the RNA in the cleavage and blastula stages is most likely due to an increase in the length of the existing poly(A) tail. 


\section{$\begin{array}{lllllllll}1 & 2 & 3 & 4 & 5 & 6 & 7 & 8 & 9\end{array}$}

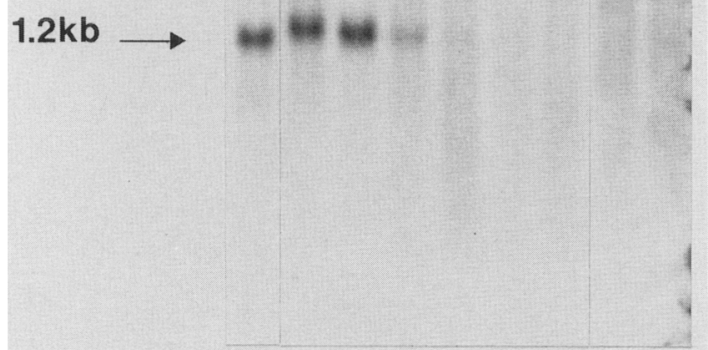

Figure 1. Northern blot analysis of Xenopus RNA probed with nick-translated clone B4.0 (Lanes 1-7) $10 \mu \mathrm{g} /$ lane of total RNA. (Lane 1) Stage VI oocyte; (lane 2) cleavage (stages 6.5-7); (lane 3) blastula (stage 9); (lane 4) gastrula (stages 10.5-12); (lane 5) neurula (stages 17-20); (lane 6) early tailbud (stages 24-26); (lane 7) 3-day-old tadpole (stages 37-41); (lane 8) $0.8 \mu \mathrm{g}$ of liver poly $\mid \mathrm{A})^{+}$RNA; (lane 9) $0.4 \mu \mathrm{g}$ of muscle poly $(\mathrm{A})^{+}$RNA.

\section{Characterization and sequencing of two B4 CDNA clones}

The first B4 clone (B4.0; originally B4) was isolated from a Xenopus total ovary cDNA library (Dworkin et al. 1985 ) and has an insert of $793 \mathrm{bp}$. Since the B4 mRNA is approximately $1.2 \mathrm{~kb}$ in length, the clone B4.0 is incomplete. Screening of a Xenopus egg cDNA plasmid library for B4 sequences resulted in the isolation of a further clone, B4.1. This cDNA contains 894 bp of B4 sequence plus a poly(A) tail. The relationship between the two clones (based on their sequence, see below) is shown in Figure $2 \mathrm{~A}$. B4.1 has $387 \mathrm{bp}$ of additional sequence at the 3 ' end compared with B4.0, but it lacks 286 bp of sequence at the $5^{\prime}$ end that is present on B4.0. Together the two clones cover $1180 \mathrm{bp}$ of sequence, excluding the poly(A) tail. Thus, virtually all of the B4 mRNA sequences should be contained within these two clones. Both B4.0 and B4.1 have been fully sequenced (Fig. 2B). Within the 507-nucleotide overlap between the two clones, five nucleotide differences were found (Fig. 2); four are base substitutions at positions 295, 337, 574, and 614, and one is an extra nucleotide at position 673 in B4.1 which was absent from B4.0. The two clones could be derived from different alleles of a single B4 gene, or represent two different $B 4$ genes. The partial duplication of the $X$. laevis genome during its evolutionary history has resulted in increased genetic variability (Thiébaud and Fischberg 1977). Furthermore, many genes in $X$. laevis are polymorphic (Okada et al. 1985).

Sequencing revealed one major open reading frame (ORF) in the B4 sequence (Fig. 2B) on the DNA strand that was confirmed to be the sense strand by hybridization of single-strand probes to B4 mRNA in Northern blots of oocyte poly(A) ${ }^{+}$RNA (data not shown). There are 277 nucleotides of $5^{\prime}$ noncoding region before the ATG codon. This ATG lies within a reasonable sequence context for translation initiation (Kozak 1987), and the presence of an upstream in-frame stop codon indicates this to be the beginning of the coding region. The B4.1-type sequence has the coding capacity for a protein of 273 amino acids, followed by 84 bp of 3' noncoding sequence, with the polyadenylation signal AATAAA 24 nucleotides upstream of the poly(A) tail.

The four base substitutions between B4.0 and B4.1 are all in the coding region of the $\mathrm{B} 4$ protein and are silent changes. However, the missing nucleotide in B4.0 at position 673 causes a frameshift that results in a stop codon two amino acids later. This ORF would produce a protein of 134 amino acids sharing 132 amino acids with the B4.1 predicted protein but missing the very basic carboxyl half of the B4.1 protein (see below). The proportion of B4 mRNA in oocytes that contains the extra nucleotide at position 673 was determined by Northern analysis using 19-mer oligodeoxynucleotides covering the region around position 673 as probes. One of these oligomers was of B4.1 type (containing a nucleotide at position 673) and one of B4.0 type (lacking a nucleotide at position 673). Conditions under which labeled 19-mer B4 anti-sense oligomers (1014, 1015; Materials and methods; Fig. 2B) only hybridized to the perfectly matching template were established using as templates SP6 RNA transcripts that contained the B4 sequence around nucleotide 673 of the B4.1 or B4.0 type (Material and methods). Under these conditions oocyte poly $(\mathrm{A})^{+}$ RNA hybridized predominantly to the B4.1-type oligomer (1015) and very little, if at all, to the B4.0-specific oligomer (1014) (Fig. 3, lane O, 1.2-kb transcript arrowed). This demonstrates that the majority of B4 mRNA molecules contain a nucleotide at position 673 and that the larger ORF represents the major B4 translation product. B4 molecules lacking a nucleotide at position 673 must either be a minor B4 mRNA species, or

Figure 2. (See following page.) (A) Relationship between B4.0 and B4.1 cDNA clones. Below the horizontal line representing the clones are the nucleotide positions of the beginning and end of the separate cDNAs. The nucleotide differences between the two clones are shown with their respective nucleotide positions. $\left({ }^{\star}\right)$ Absence of a nucleotide. $(B)$ Nucleotide sequence of B4 cDNA and predicted amino acid sequence of B4 protein. The sequence is a composite of the B4.0 and B4.1 cDNA insert sequences. Numbering of nucleotides starts at the first nucleotide of the B4.0 clone. At five nucleotide positions there was a disparity in sequence between the two clones; the sequence of the B4.1 clone is given with the B4.0 nucleotide written above. $\left({ }^{\star}\right)$ Nucleotide position that is absent from the B4.0 clone. The predicted amino acid sequence (three-letter code) is shown underneath the major open reading frame. Numbering of amino acids starts from the first amino acid of the B4 protein. The change in open reading frame caused by the absence of a nucleotide $(*)$ in the B4.0 insert is shown beneath. $\left(^{\star \star *}\right)$ Stop codon of the B4.0 reading frame. The three direct amino acid repeats toward the carboxyl end are indicated by dashed arrows. The polyadenylation signal AATAAA is dot-underlined. The nucleotide sequence underlined at position 663-682 is that contained within the oligonucleotides used as hybridization probes (the first nucleotide was only present in the B4.0 type oligonucleotide; Materials and methods). 
A.

$295337 \quad 574614673$

B4.0 $5^{\circ}$

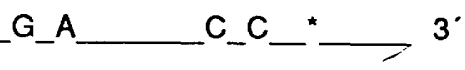

793

B4.1

$5^{\circ}$ A_T $^{-}$

G A T

$\operatorname{poly}(A) 3^{\prime}$

287

1180

B.

ggaggacagaagatcttgggttaattctat cact cctgcaaatctt ctttagtttcagtaaat cgtcattctcgccattggccgt 87 taatgctgatt caacctgttgcaat gggct tgtaacccgccagctgcttagct agatct ctgccatcgcgccgct ct ct cgtct 174 cacagacttagtt cccgacaacctctgcggcgtct cgcgagact tctccgcgctt tcgagtcgeccegccetcaacgetgacggtt 261

ctctgttgattctcaatg get cet aag aag gca gtt gct gca cct gag gga ggc aac aag gaa aat gca 331 met ala pro lys lys ala val ala ala pro glu gly gly asn lys glu asn ala 18

a

gca gtt aaa gga tcc agt aaa gtt aag gtt aaa aga aaa tct atc aaa cta gtc aag acc caa tca 397 ala val lys gly ser ser lys val lys val lys arg lys ser ile lys leu val lys thr gin ser 40

cat ccc cca acc ctg tcg atg gtg gtg gag gtc ctg aaa aag aac acg gag cgg aaa ggg acc tct 463 his pro pro thr leu ser met val val glu val leu lys lys asn thr glu arg lys gly thr ser 62

gtg cag gcc att cgg acc cgg att ctg tct gca cat ccc aca gtg gat cca ctg agg ctg aag ttt 529 val gln ala ile arg thr arg ile leu ser ala his pro thr val asp pro leu arg leu lys phe 84

ttg cta cgg acg gcc ctg aac aa ggg cta gag aag ggg att ctg atc aga cct cta aac tct agt 595 leu leu arg thr ala leu asn lys gly leu glu lys gly ile leu ile arg pro leu asn ser ser 106

gca aca gga gct aca gga aga ttc aa ctt gcc aaa cca gta aaa act aca aag gct ggg aaa gaa 661 ala thr gly ala thr gly arg phe lys leu ala lys pro val lys thr thr lys ala gly lys glu 128

aat ata ged tet gaa aac gta gac cca aat gca gag cag gaa acc caa aag aag gcc cca aag aaa 727 asn val ala ser glu asn val asp pro asn ala glu gln glu thr gln lys lys ala pro lys lys 150

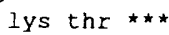

gaa aag aaa gcg aag act gag aaa gaa ccc aaa ggt gag aaa acc aaa gct gta gct aaa aag gcc 793 glu lys lys ala lys thr glu lys glu pro lys gly glu lys thr lys ala val ala lys lys ala 172

aag gaa gat tct gat gaa aaa ccc aaa gtt gcc aaa tct aag aaa gat aaa gag gca aaa gaa gtt 859 lys glu asp ser asp glu lys pro lys val ala lys ser lys lys asp lys glu ala lys glu val 194

gac aag gct aat aaa gag gca aaa gaa gtt gac aag gct aat aaa gag gca aaa gaa gtt gac aag 925 asp lys ala asn lys glu ala lys glu val asp lys ala asn lys glu ala lys glu val asp lys 216 -

gct ccg gca aag aaa cca aaa gcc aaa aca gag gct gcg aaa get gag ggg ggt ggc aag gca aag 991 ala pro ala lys lys pro lys ala lys thr glu ala ala lys ala glu gly gly gly lys ala lys 238 $-\rightarrow$

aag gag ccc cca aag gcc aaa gcc aag gac gtg aaa gca cag aag gac tct aca gat gaa ggt gct 1057 lys glu pro pro lys ala lys ala lys asp val lys ala gln lys asp ser thr asp glu gly ala 260 cca gtt aag gct ggc aag aaa gga aag aaa gtg aca aac taggctgatatactttaactctgtaatctggtt 1131 pro val lys ala gly lys lys gly lys lys val thr asn

Figure 2. (See previous page for legend.) 


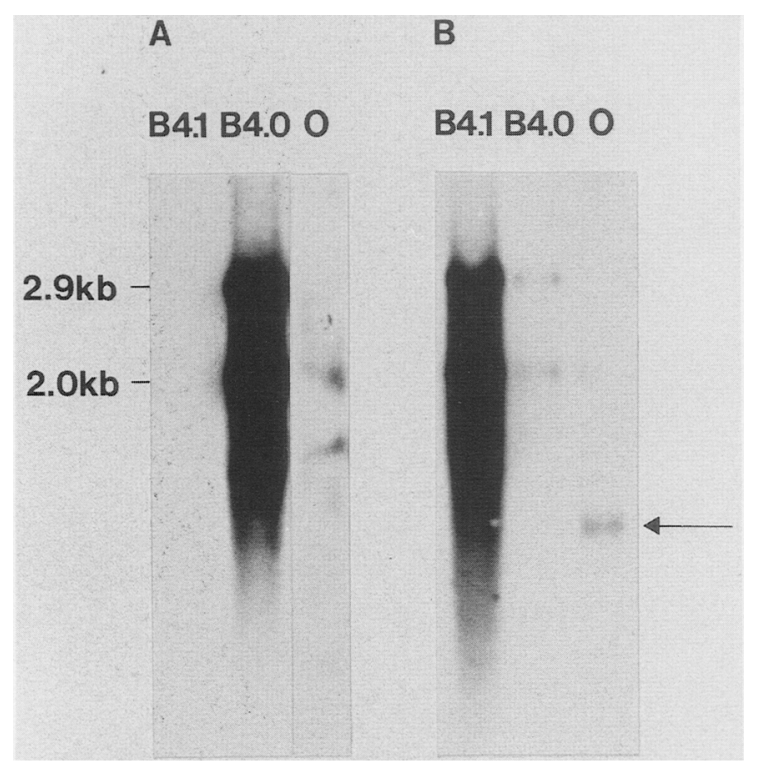

Figure 3. Differential hybridization of oligodeoxynucleotides to B4 SP6 transcripts and oocyte poly $(\mathrm{A})^{+}$RNA. Hybridization under differential hybridization conditions to SP6 transcripts $(\sim 150 \mathrm{ng} /$ lane) of the B4.1 type (B4.1) or B4.0 type (B4.0) and to oocyte $(\mathrm{O})$ poly $(\mathrm{A})^{+}$RNA ( $3 \mu \mathrm{g} / \mathrm{lane}$ ) using as probes oligonucleotide 1014 (B4.0 type) (A) and oligonucleotide 1015 (B4.1 type) $(B)$ (Materials and methods). (Arrow) Position of the 1.2-kb B4 mRNA. Both hybridizing bands in the SP6 transcript lanes are in vitro transcription products that contain the $\mathrm{B} 4 \mathrm{se}-$ quence. The two left lanes in $A$ are 6-hr autoradiographic exposures; all remaining lanes are 18 -hr exposures.

the absence of this nucleotide in the B4.0 clone is artifactual. The designation ' $\mathrm{B} 4$ ' will be used to refer to the sequence containing the longer ORF.

The $\mathrm{B} 4$ sequence has the coding capacity for a protein of $29,290 \mathrm{kD}$. The amino acid content of the B4 protein is unusual in that it is $25 \%$ lysine, with most residues in the carboxy-terminal portion of the protein; there are no cysteine, tyrosine, or tryptophan residues. Overall the $\mathrm{B} 4$ protein is very basic, with a calculated $\mathrm{pI}$ of 10.62 . A hydropathy plot of the B4 protein is shown in Figure 4. The B4 protein consists of three major domains: a central hydrophobic domain (region B) flanked by an aminoterminal domain (region A) and a carboxy-terminal domain which is strikingly hydrophilic (region C). In the carboxy-terminal domain of the protein are three tandemly repeated amino acid motifs, which are also exact repeats at the nucleotide level, and consist of two direct repeats of 10 amino acids followed by an incomplete repeat of 9 amino acids (Fig. 2B).

Searches of a protein data base with the $\mathrm{B} 4$ protein sequence revealed low but significant similarities with histone $\mathrm{Hl}$ proteins from a wide range of organisms, including plants, birds, mammals, fish, invertebrates, as well as amphibians (Table 1). The homology is throughout the coding region. Of the three histone $\mathrm{H} 1$ subtypes in Xenopus embryos, histone H1B shows the best alignment (29\% amino acid identity) and is illustrated in Figure 5. A string of five identical amino acids

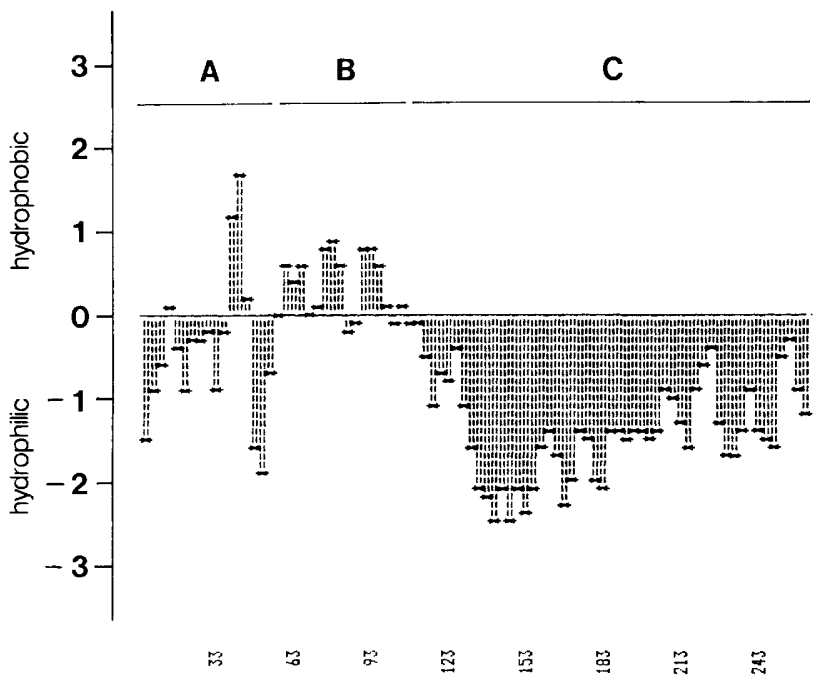

Figure 4. Hydropathy plot of the B4 protein. Numbers along the abscissa represent the amino acid positions of the B4 protein, with numbering starting at the amino terminus. The ordinant shows the hydropathic index. The segment length for analysis was 9 (Material and methods). A, B, and C are the three major domains of the B4 protein (Results).

is the longest consecutive match. B4 also shows comparable similarities to the two other Xenopus histone H1 subtypes: $\mathrm{HIC}$ ( $28 \%$ in 181 amino acid overlap) and H1A (25\% in 206 amino acid overlap). These Xenopus H1 subtypes show $75-80 \%$ identity with each other (Turner et al. 1983; Perry et al. 1985).

\section{Isolation of B4-specific antibodies and immunocytochemistry}

Antibodies to the $\mathrm{B} 4$ protein were raised via production of an $E$. coli B4- $\beta$-galactosidase fusion protein. An expression vector was constructed that contained the $1 a c Z$ gene fused to the B4.0 sequence in frame to yield upon translation amino acids $23-132$ of the B4 protein fused to the carboxy-terminal end of $\beta$-galactosidase. The fusion protein was used to immunize rabbits, and antibodies against the B4 part of the fusion protein were isolated by affinity chromatography (Materials and methods).

Immunocytochemistry of paraffin-embedded Xenopus embryo sections using the affinity-purified anti-B4 antibodies and a fluoresceinated secondary antibody revealed staining of the nuclei of early embryos (Fig. 6A,B). The same pattern of staining was seen at stage 7 using three different fixatives, including precipitant and crosslinking types (data not shown). All nuclei appeared to stain equally. Nuclear labeling was bright in eight-cell embryos (the earliest stage examined; data not shown), as well as at later cleavage and blastula stages. By the gastrula stage labeling was in general fainter, and in neurulae and later stages (stages 24-27, stages 40-41) labeling was no longer detectable (Fig. 6B and data not shown). Labeling was absent from a range of adult 
Table 1. Sequence similarity of B4 protein to the histone H1 family of proteins

\begin{tabular}{lllc}
\hline & $\begin{array}{l}\text { Code } \\
\text { or } \\
\text { Protein }\end{array}$ & $\begin{array}{l}\text { Sequence } \\
\text { identity } \\
(\%)\end{array}$ & $\begin{array}{l}\text { Amino acid } \\
\text { overlap }\end{array}$ \\
\hline Frog histone H1B & HSXL1B & 29 & 219 \\
Frog histone H1A & HSXL1A & 25 & 206 \\
Frog histone H1C & a & 28 & 181 \\
Rainbow trout histone H1 & HSTR1R & 29 & 181 \\
Gonadal sea urchin histone H1 & HSUR1P & 28 & 178 \\
Rat testis-specific histone H1 & b & 25 & 201 \\
Trout histone H1 & HSTR1 & 27 & 166 \\
Goose histone H5 & HSGS5 & 31 & 108 \\
Pea histone H1 & c & 35 & 107 \\
Human histone H1 & A24850 & 116 \\
\hline
\end{tabular}

The code for a particular protein is its entry name in the PIR sequence data bank (Release 10.0). For proteins not listed in the PIR, the reference containing the sequence is: (a) Turner et al. (1983); (b) Cole et al. (1986); (c) Gantt and Key (1987).

tissues tested (liver, kidney, leg muscle, heart, brain; data not shown). Cleavage-stage sections have a high proportion of nuclei at the metaphase stage of mitosis, and these nuclei showed a similar staining pattern with the DNA stain DAPI as with the anti-B4 antibodies (Fig. $6 \mathrm{~B}, \mathrm{a})$, indicating that the $\mathrm{B} 4$ antigen is associated with the chromosomes. In the unfertilized egg the one set of metaphase chromosomes stained brightly (data not shown). In the stage VI oocyte the germinal vesicle was slightly brighter than background (data not shown) but since the chromatin is only partially condensed it was difficult to be certain whether the chromosomes themselves were stained. Identical results were obtained with anti-B4 antibodies purified from serum of two separate rabbits. Anti- $\beta$-galactosidase antibodies at the same concentration as the B4-specific antibodies gave a negative reaction to all sections tested (data not shown).

Because the B4 protein and Xenopus histone $\mathrm{Hl}$ exhibit amino acid similarity, the possibility existed that the observed staining of nuclei was due to cross-reaction

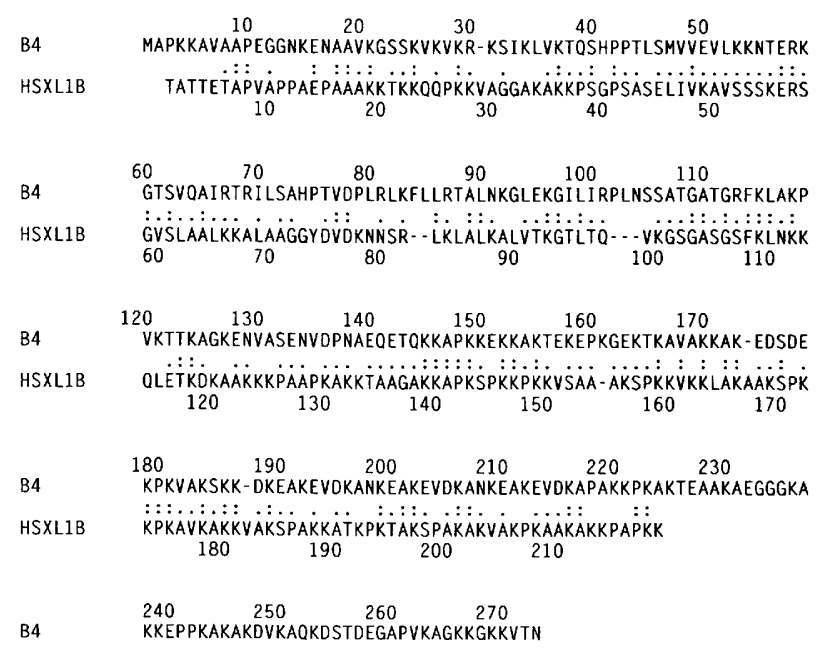

Figure 5. Comparison of B4 protein with Xenopus histone HIB (HSXL1B). Double dots indicate identity and single dots indicate conservative replacements. of the anti-B4 antibodies to endogenous histone $\mathrm{H} 1$. To test this, rabbit antiserum raised against Xenopus histone $\mathrm{H} 1$ (a gift of Dr. A. Moorman) was reacted to Xenopus sections. This antiserum labeled nuclei at all stages tested (egg, blastula, gastrula, neurula, tailbud, and tadpole), with the later stages showing the brightest labeling (Fig. 6C and data not shown). This result proved that the B4 staining pattern was not due to cross-reaction to endogenous histone $\mathrm{Hl}$ and demonstrated that the nuclei of post-gastrula stages were fully accessible to antibody staining.

\section{Immunoblotting}

Anti-B4 antibodies, even at low dilutions $(\sim 15 \mu \mathrm{g} / \mathrm{ml})$, did not label any protein in Western blots of total Xenopus embryonic lysates. Therefore, to visualize B4 protein on Western blots it was necessary to prepare samples enriched in B4 protein. Immunoblotting of nuclear extracts from cleavage embryos showed staining of one major band at $36 \mathrm{kD}$ and two minor bands at $34 \mathrm{kD}$ and $40 \mathrm{kD}$ (Fig. 7A). Staining with anti-B4 antibodies isolated from a different rabbit (rabbit 2) stained the major $36-\mathrm{kD}$ band as well as the $40-\mathrm{kD}$ minor band but not the 34-kD band (Fig. 7B and data not shown). Anti- $\beta$ galactosidase antibodies at the same concentration did not label these proteins (Fig. 7A). The 36-kD band probably represents the $\mathrm{B} 4$ protein, as it is the major band recognized by both sera. The minor band(s) could be due to post-translational modification of the protein affecting its mobility, or cross-reaction of the antibodies to B4-related proteins. The higher molecular weight than predicted from sequencing $(29 \mathrm{kD})$ is not surprising since many histone and nuclear proteins are retarded on gels due to their unusual amino acid composition (Bürglin et al. 1987). The very basic carboxyl terminus of B4 (and histone H1) (Fig. 4) suggested that advantage could also be taken of solubility in $5 \%$ perchloric acid as a method of enrichment of B4 (Materials and methods). Immunoblots of perchloric acid extracts from total embryos (Fig. 7B) showed reaction (with antibodies from rabbit 2) to a $36-\mathrm{kD}$ protein and a $40-\mathrm{kD}$ protein in all 
stages tested (from oocyte to early tailbud embryo), although the relative intensities of these two proteins changed through development. Anti-histone $\mathrm{Hl}$ antiserum labeled a protein migrating at $\sim 31 \mathrm{kD}$ in these perchloric acid extracts (Fig. 7C). The presence of B4 protein in the oocyte is consistent with the partial polysomal distribution of B4 RNA at this stage (Dworkin et al. 1985). Since the level of B4 mRNA declines rapidly between the oocyte and neurula, whereas the B4 protein level remains approximately constant, the protein itself appears to be relatively stable. However, although the total amount of B4 protein per embryo remains unchanged during early development, the amount of B4 protein per nucleus decreases substantially as cell division proceeds.

\section{Discussion}

B4 mRNA is a moderately abundant Xenopus RNA that is expressed during oogenesis and the first day of embryonic development. Sequencing of two independently isolated B4 cDNA clones has revealed the putative amino acid sequence of the $\mathrm{B} 4$ protein. The $\mathrm{B} 4$ protein shows a weak sequence similarity to histone $\mathrm{H} 1$, an identity of about $25-30 \%$ over the entire length of the protein. Although histone $\mathrm{H} 1$ proteins are the least conserved of the histone family, nevertheless histone $\mathrm{Hl}$ subfamily members are highly homologous. In Xenopus embryos the three known histone $\mathrm{Hl}$ subtypes (HlA, $\mathrm{H} 1 \mathrm{~B}, \mathrm{H1C}$ ) are $75-80 \%$ identical at the amino acid level (Turner et al. 1983; Perry et al. 1985). The central globular domain of the histone $\mathrm{Hl}$ molecule is the most conserved region of the histone $\mathrm{H} 1$ protein $170 \%$ identity in all animal histone $\mathrm{Hl}$ proteins, with $90-100 \%$ conservation around a phenylalanine residue within the globular domain; Coles et al. 1987; Gantt and Key 1987), but B4 has no higher similarity to this part of the $\mathrm{H} 1$ molecule than to any other. However, the B4 protein does possess the tripartite structure characteristic of histone $\mathrm{Hl}$; a central globular hydrophobic core surrounded by an amino-terminal segment and a carboxy-terminal hy- drophilic tail. The larger size of the $\mathrm{B} 4$ protein $(29 \mathrm{kD})$ compared to the characterized animal histone $\mathrm{Hls}$ $(20-25 \mathrm{kD})$ is due mainly to longer carboxy- and aminoterminal domains. The presence of three carboxy-terminal direct amino acid repeats in B4 is also a feature of histone Hl proteins (Von Holt et al. 1979; Mezquita et al. 1985); however, the sequence of the B4 repeat is not similar to any known repeat in histone $\mathrm{Hl}$.

Despite similarities between $\mathrm{B} 4$ and histone $\mathrm{H} 1$ at the protein level, B4 mRNA does not show histone-like features. The B4 mRNA does not contain the $3^{\prime}$ dyad symmetry sequence that is thought to be involved in RNA processing; neither does it contain the second further downstream purine-rich $3^{\prime}$ sequence element conserved in histone Hl mRNAs (Krieg and Melton 1984; Coles et al. 1987). The B4 mRNA contains a classic polyadenylation signal in the $3^{\prime}$ noncoding sequence and the message is known to be polyadenylated. This is in contrast to histone mRNAs, which generally do not contain a polyadenylation signal and lack a poly(A) tail. As an exception to this generality, the majority of Xenopus histone mRNA is polyadenylated in the oocyte (Ruderman et al. 1979|, but these polyadenylated histone mRNAs lack a polyadenylation signal (Ballantine and Woodland 1985). A further difference between $\mathrm{B} 4$ and histone $\mathrm{H} 1 \mathrm{~s}$ is the gene frequency in the genome. Southern analysis of the B4 gene shows a pattern typical of low-copy-number genes (E. Dworkin-Rastl and M. Dworkin, unpubl.), in contrast to each of the Xenopus histone $\mathrm{Hl}$ genes which are reiterated in the genome 10-25 times (Perry et al. 1985).

In situ immunofluorescence experiments using antibodies raised against a bacterial B4 fusion protein showed that the B4 protein is localized in the nuclei of early embryos until the gastrula stage, after which it is no longer detectable. The B4 protein was clearly chromatin-associated during mitotic metaphase in cleavage embryos. Immunoblotting showed that the $\mathrm{B} 4$ protein is inherited maternally and persists at approximately constant levels from the oocyte to the early tailbud stage. Thus, during early cleavage stages, before the amount of

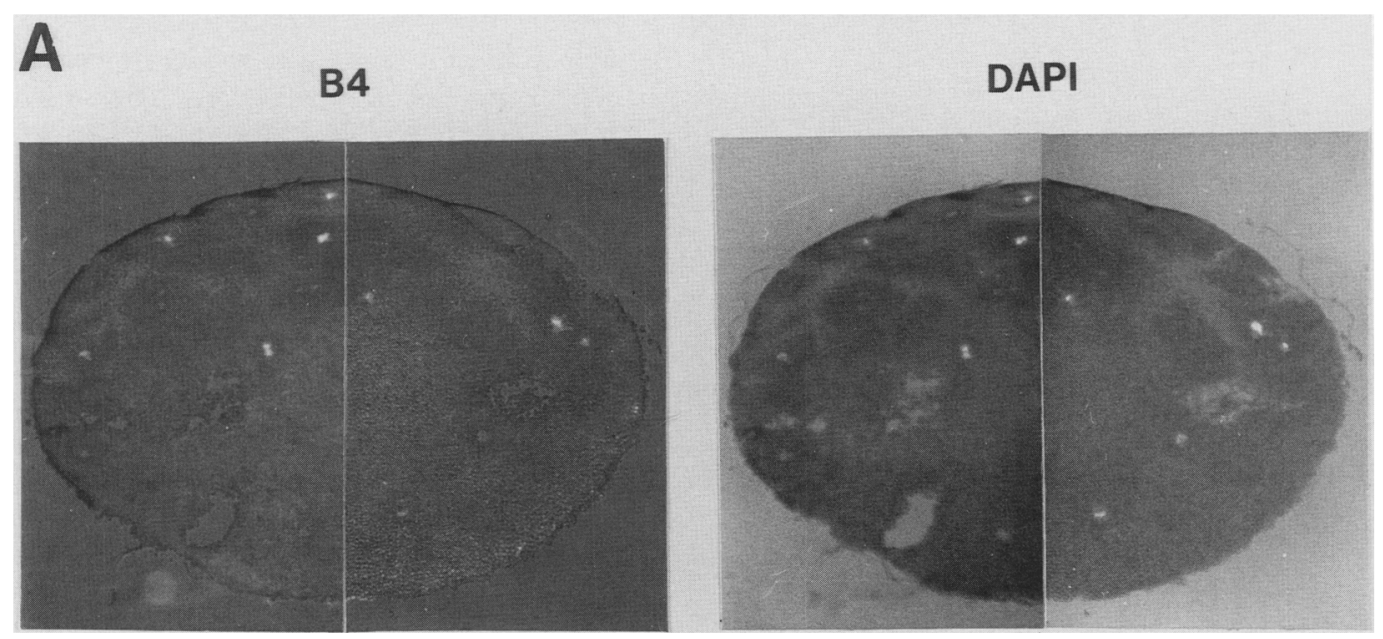

Figure 6. (Continued on following page.) 
Smith et al.

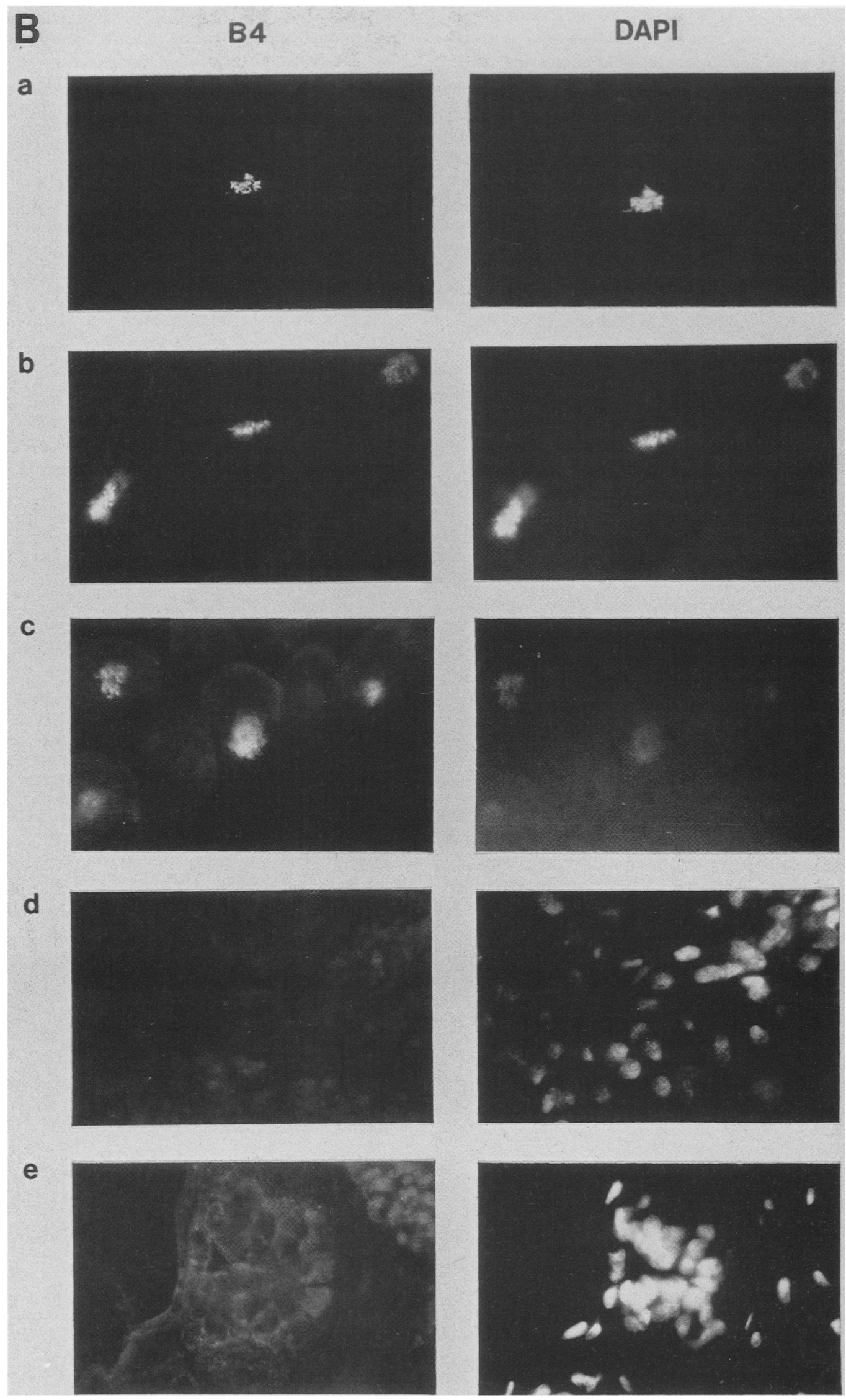

Figure 6. (See facing page for legend.) 


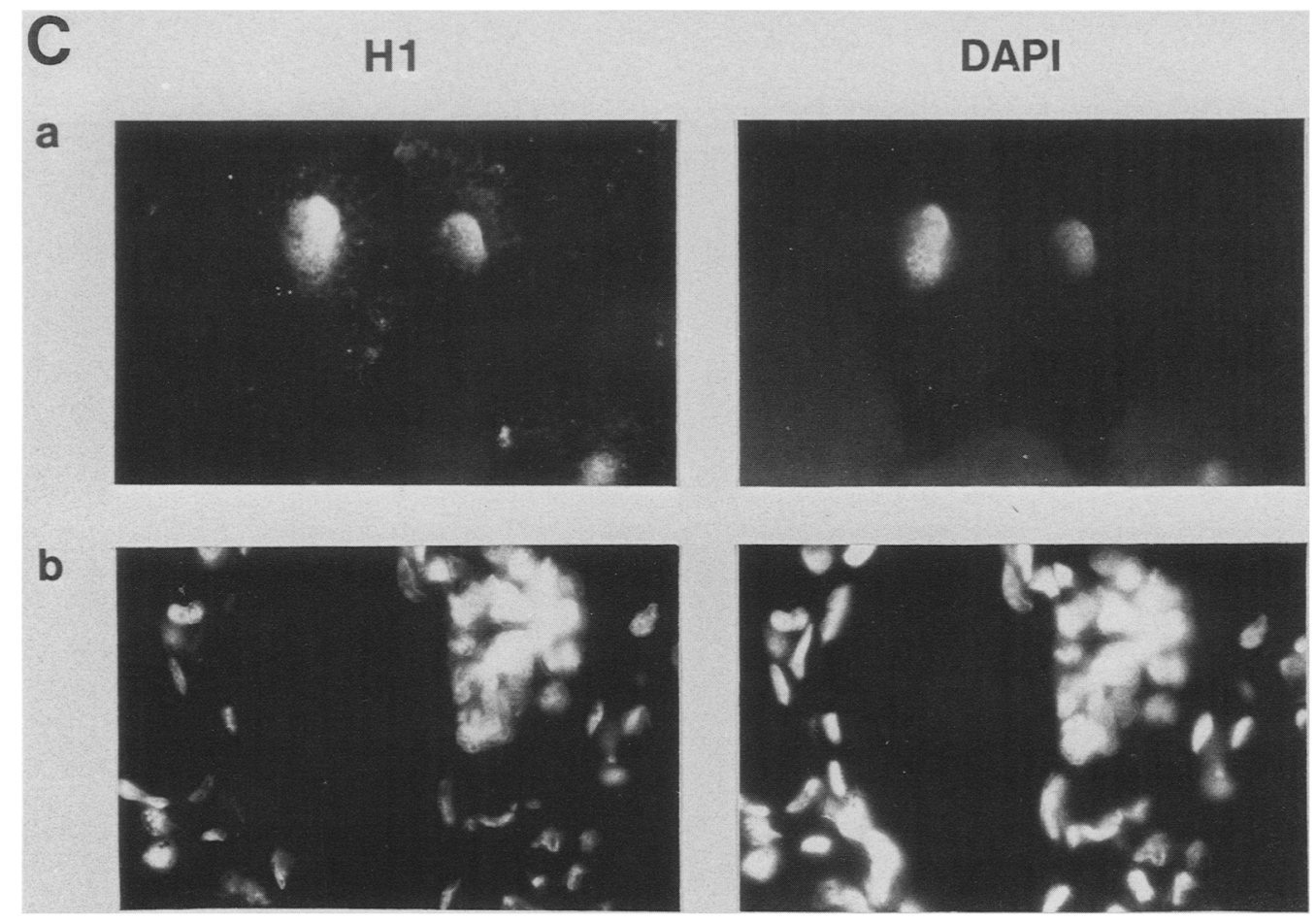

Figure 6. Immunocytochemistry of Xenopus sections. Paraffin-embedded Xenopus tissue sections were stained with either B4-specific antibodies $(A$ and $B, \sim 80 \mu \mathrm{g} / \mathrm{ml})$, or Xenopus anti-histone $\mathrm{Hl}$ antiserum $\{C, 1: 100$ dilution $)$ and visualized with a fluoresceinated secondary antibody. Left-hand-side panels show antibody staining; right-hand-side panels show counterstaining of the same section with DAPI. The length of photographic exposure in seconds for each of the antibody : DAPI pairs, respectively, is given in parentheses $(\exp . \mathbf{x}, \mathbf{x})$ below. $(A)$ Low-power view of a cross-section of a blastula embryo (stage 8 ) with animal hemisphere at the top of the picture (exp. 60,8). The embryo is approximately $1.2 \mathrm{~mm}$ in diameter. $(B)$ High-power view $(6.3 \times$ higher magnification than in $A\}$ of: (a) cleavage (stage 6.5$)$, centering on a set of metaphase chromosomes $\{$ exp. 60,8$) ;(b)$ blastula (stage 8$)(\exp .60,8) ;(c)$ gastrula $(\mathrm{stages}$ 11-11.5) (exp. 60,15); (d) neurula (stage 19) (exp. 60,8); (e) 3-day-old tadpole (stages 40-41), centering on neural tube (exp. 240,4). $(C)$ High-power view of: $(a)$ blastula (stage 8$)$ (exp. 60,8); (b) 3-day-old tadpole (stages 40-41) (exp. 30,8).

chromatin increases sufficiently to bind all available B4 protein, there must be $\mathrm{B} 4$ protein in the embryo not associated with chromatin. Such extrachromosomal stores, however, were not detected immunocytochemically, and therefore are probably not localized. The failure to detect B4 protein in nuclei from later stages is probably a result of the decrease in amount of $B 4$ protein per nucleus due to its distribution into increasing numbers of nuclei as development proceeds.

There is little evidence for developmentally specific histone $\mathrm{Hl}$ variants in Xenopus, except for the description by Koster et al. (1979) of a cleavage-specific lysinerich protein (Destrée et al. 1973; Flynn and Woodland 1980; Risley and Eckhardt 1981; Perry et al. 1986). However, histone $\mathrm{H} 1$ variants specific to early development have been described in the sea urchin (Levy et al. 1982) and mud-snail (Flenniken and Newrock 1987), and specific to the testis in rat (Cole et al. 1986). The best-characterized sea urchin variants conform to standard histone family characteristics and show high sequence similarity to the other sea urchin histone $\mathrm{H} 1$ proteins (Levy et al. 1982). The divergence of $\mathrm{B} 4$ protein and mRNA from the histone $\mathrm{H} 1$ family suggests that $\mathrm{B} 4$ should be considered either a distant member of the histone $\mathrm{H} 1$ family or a novel protein with histone $\mathrm{H} 1$ characteristics.

About 8-10 ng of histone HlA protein is inherited by the Xenopus embryo from the oocyte, sufficient theoretically to provide the newly synthesized chromatin in embryos with histone $\mathrm{H} 1$ until the early blastula stage (Van Dongen et al. 1983). The translation of stored histone $\mathrm{H} 1 \mathrm{mRNA}$ is not significant until late cleavage stages (Woodland et al. 1979; Flynn and Woodland 1980). Despite the presence of $\mathrm{Hl}$ protein in the early embryo it is not clear when it is actually incorporated into chromatin. Destrée et al. (1973), examining histones in chromatin from late blastula and gastrula embryos, showed that histone $\mathrm{Hl}$ was underrepresented relative to the other histones until the neurula stage, when it reached its expected proportion. Experiments on chromatin assembly in extracts from unfertilized eggs showed an absence of histone $\mathrm{H1}$; nevertheless the chromatin of nuclei assembled in Xenopus egg extracts displayed the nucleosome digestion patterns typical of histone H1-containing chromatin (Dilworth et al. 1987). These data suggest that an unknown histone $\mathrm{Hl}$ variant may exist in Xenopus eggs and early embryos. It is intriguing to speculate that $\mathrm{B} 4$ is this protein. 


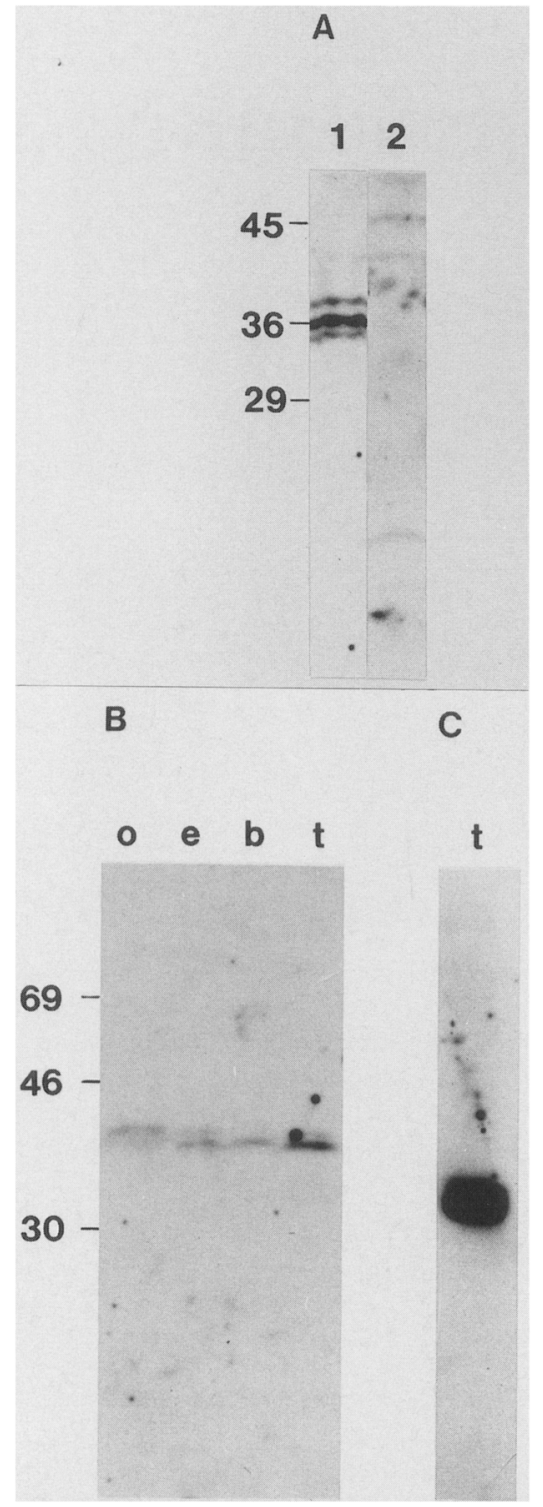

Figure 7. Immunoblotting of an embryonic nuclear extract and perchloric acid protein extracts. (A) A Western blot of a nuclear extract from preneurula embryos was probed with B4specific antibodies $(\sim 15 \mathrm{mg} / \mathrm{ml})$ (lane 1$)$ or $\beta$-galactosidase-specific antibodies $(\sim 15 \mathrm{mg} / \mathrm{ml})$ (lane 2$).(B, C)$ Western blots of perchloric acid extracts from stage VI oocytes (lane o), unfertilized eggs (lane $e$ ), stage 9 blastulae (lane $b$ ), and stages 26-27 early tailbud embryos (lane $t$ ) were probed with anti-B4 antibodies $(\sim 15 \mathrm{ml}$, derived from a different rabbit from those in $A)(B)$; or Xenopus anti-Hl antiserum $(1: 500$ dilution $)(C)$. $(B)$ Five-day autoradiographic exposure; (C) 18-hr autoradiographic exposure. Antibodies were visualized with ${ }^{125} \mathrm{I}$-labeled protein A. The numbers on the left refer to the molecular weight in kilodaltons.

\section{Materials and methods \\ RNA extraction and Northern analysis}

Oocytes were staged according to Dumont (1972) and embryos according to Nieuwkoop and Faber (1967). RNA extraction was performed as described previously (Dworkin and Dawid 1980). Poly $(\mathrm{A})^{+}$RNA was isolated and Northern analysis with plasmid probes was carried out as described previously (Dworkin et al. 1985) with hybridization and washing conditions as detailed by Church and Gilbert (1984).

\section{Construction and screening of an egg cDNA library}

An egg cDNA plasmid library was prepared from poly $(A)+$ RNA isolated from unfertilized eggs as described under RNA extraction, except that the RNA was not digested with DNase. Synthesized double-stranded cDNA (Gubler and Hoffman 1983) was size-fractionated by passage over a Sepharose $4 \mathrm{~B}$ column and cDNA larger than $\sim 500$ bp was inserted into the PstI site of pGEM4 (Promega) using oligo/dG:dC) tailing. Clones of the egg cDNA library were screened for B4 clones using as probe a nick-translated 549-bp PvuII-AccI fragment of B4.0 (nucleotides $133-681$ in Fig. 2B). The final wash stringency of the filters was $0.2 \times \mathrm{SSC}, 1 \%$ SDS at $65^{\circ} \mathrm{C}$.

\section{DNA sequencing and computer programs}

The majority of DNA sequencing was performed using the method of Maxam and Gilbert (1980) with labeling of DNA fragments as described previously (Dworkin-Rastl et al. 1984). Some sequences were obtained by the chain-termination method with double-stranded DNA templates (Chen and Seeburg 1985) performed with a Sequenase sequencing kit (USB) and using an SP6 primer (for inserts cloned into PGEM vectors) or a primer oligodeoxynucleotide of $\mathrm{B} 4$ sequence.

Homology searches of the protein sequence database of the Protein Identification Resource data bank (Release 10.0) were performed using the FASTP program (Lipman and Pearson 1985). Construction of the hydropathy plot, based on the method of Kyte and Doolittle (1982), and calculation of the pI value were performed using a DNA/Protein Sequence Analysis software package (IBI).

\section{Differential oligonucleotide hybridization}

Oligodeoxynucleotides were synthesized with an Applied Biosystems DNA synthesizer, purified by reverse-phase HPLC following the protocol of Applied Biosystems, and dissolved in water.

SP6 RNA transcripts of $2.0 \mathrm{~kb}$ and $2.9 \mathrm{~kb}$, produced by standard methods (Melton et al. 1984), contained 19 nucleotides of sense $\mathrm{B} 4.0$ or $\mathrm{B} 4.1$ sequence centered at the position of the extra nucleotide in clone B4.1 (position 673; Fig. 2B). They were used as template RNAs to determine differential hybridization conditions such that a 19 -mer antisense B4.0 oligomer $\left\{5^{\prime}\right.$ labeled with T4 polynucleotide kinase to a specific activity of $5000 \mathrm{Ci} /$ mmole) only hybridized to the B4.0-type RNA and not to the B4.1-type, and vice versa (B4.0-specific probe, oligonucleotide 1014, 5' -TACGTTTTCGACGCTACAT-3'; B4.1-specific probe, 1015, 5'-TACGTTTTCAGACGCTACA-3' Fig. 2B). Differential hybridization conditions were obtained by hybridization overnight at $45^{\circ} \mathrm{C}$ in $1 \%$ BSA, $7 \%$ SDS, $1 \mathrm{mM}$ EDTA, $0.75 \mathbf{~}$ $\mathrm{NaHPO}_{4}$ (pH 7.2). Filters were washed for $15 \mathrm{~min}$ in solution $\mathrm{A}$ $(0.9 \mathrm{M} \mathrm{NaCl}, 0.09 \mathrm{M} \mathrm{Na}$-citrate, $5 \%$ SDS, $0.5 \% \mathrm{BSA})$ at room temperature $(R T), 15 \mathrm{~min}$ in solution $\mathrm{B}(0.9 \mathrm{M} \mathrm{NaCl}, 0.09 \mathrm{M}$ Na-citrate, $1 \% \mathrm{SDS}$ ) at RT, and then $5 \mathrm{~min}$ in $200 \mathrm{ml}$ of solution $\mathrm{B}$, which was initially heated to $65^{\circ} \mathrm{C}$ but cooled down as washing was carried out at RT. Northern analysis of oocyte poly $(\mathrm{A})^{+}$RNA ( $3 \mu \mathrm{g} /$ lane) was carried out under these conditions with labeled B4.1 and B4.0 oligomers as probes $\left(10^{6} \mathrm{cpm} /\right.$ lane). 
Expression vector construction and fusion protein isolation

The 1.37-kb BamHI-PstI fragment from B4.0, which contained the sequence from position 342 of $\mathrm{B} 4$ sequence (Fig. $2 \mathrm{~B}$ ) to the end of the B4.0 insert plus 778 bp of pBR322 sequence, was cloned into the BamHI-PstI site in the polylinker of pUR291 (Rüther and Müller-Hill 1983). This resulted in the fusion of the lac $Z$ gene to the B4.0 open reading frame yielding upon translation amino acids $23-134$ of the B4.0 protein fused to the carboxy-terminal end of $\boldsymbol{\beta}$-galactosidase. E. coli strain K12 71-18 (Messing et al. 1977) was transformed with this vector and transformants were maintained on minimal medium. Fusion protein was induced by adding isopropyl- $\beta$-D-thiogalactoside (Pharmacia) to a final concentration of $1.5 \mathrm{mM}$ to log-phase bacteria $\left(\mathrm{OD}_{590}=1.0\right)$ in L-broth and growth for approximately 2 hr until $\mathrm{OD}_{590}=1.7-2.0$. Induced cultures (2.4 liters) were harvested and the bacteria lysed by resuspension in $24 \mathrm{ml}$ of 0.2 M Tris- $\mathrm{HCl}(\mathrm{pH} 7.6), 10 \mathrm{~mm} \mathrm{Mg-acetate,} 5 \%$ glycerol, $0.25 \mathrm{M}$ $\mathrm{NaCl}, 10 \mathrm{mM}$ 2-mercaptoethanol (ME), $0.5 \mathrm{mg} / \mathrm{ml}$ lyzozyme (Sigma), and repeated cycles of freezing and thawing. After centrifugation for $30 \mathrm{~min}$ at $18,000 \mathrm{rpm}$ in a Sorvall SS34 rotor, over $90 \%$ of the fusion protein was associated with the pellet fraction. This material was solubilized in $10 \mathrm{ml}$ of $8 \mathrm{M}$ urea, 50 mM Tris- $\mathrm{HCl}$ (pH 7.9), $0.5 \mathrm{M} \mathrm{NaCl}, 1 \mathrm{~mm}$ EDTA, $30 \mathrm{~mm} \mathrm{ME}, 1$ $\mathrm{mM}$ phenylmethylsulfonylfluoride (PMSF), and fractions (200 $\mu 1)$ were separated on SDS-polyacrylamide gels (Laemmli 1970), from which the fusion protein was cut out and electroeluted.

\section{Immunization protocol and antibody purification}

Rabbits were immunized with $200 \mu \mathrm{g}$ of B4 fusion protein in 1 $\mathrm{ml}$ of PBS emulsified with $3 \mathrm{ml}$ of complete Freund's adjuvant subcutaneously at multiple sites on the back. After 3-4 weeks rabbits were boosted with $100 \mu \mathrm{g}$ of fusion protein in incomplete Freund's adjuvant. A second boost of $100 \mu \mathrm{g}$ was given subcutaneously 2 weeks later. Two weeks after this, a boost of $100 \mu \mathrm{g}$ was given in a combination of subcutaneous and intravenous injections. Further boosts were given at intervals of 4 weeks to maintain high antibody titer. Bleeds $(1-3 \mathrm{ml}, 25 \mathrm{ml}$, or total exsanguination) were taken 1-2 weeks after boosts.

Serum was applied twice to a $\beta$-galactosidase affinity column to remove anti- $\beta$-galactosidase antibodies. This column was prepared by linking $\beta$-galactosidase (Sigma; $8 \mathrm{mg} / \mathrm{ml}$ resin) to $\mathrm{CNBr}$-activated Sepharose 4B (Sigma). Bound anti- $\beta$-galactosidase antibodies were eluted with $0.2 \mathrm{M}$ glycine, $0.5 \mathrm{M} \mathrm{NaCl}(\mathrm{pH}$ $2.3)$ and neutralized immediately with $1 \mathrm{M}$ Tris- $\mathrm{HCl}\langle\mathrm{pH} 9.5\rangle$. The flowthrough fraction (containing B4-specific antibodies) was applied to a B4- $\beta$-galactosidase fusion protein affinity column. This column was prepared by linking purified B4- $\beta$-galactosidase fusion protein to $\mathrm{CNBr}$-activated Sepharose $4 \mathrm{~B} / 3$ $\mathrm{mg} / \mathrm{ml}$ resin). B4-specific antibodies were eluted in a similar manner as described for the anti- $\beta$-galactosidase antibodies, precipitated, resuspended in PBS, and dialyzed extensively.

\section{Immunocytochemistry}

Oocytes, dejellied eggs, or embryos were fixed at $4^{\circ} \mathrm{C}$ overnight in $100 \%$ methanol and paraffin-embedded (Paraplast, Monoject) by standard procedures. Sections of $10 \mu \mathrm{m}$ were cut and dried onto subbed slides $10.5 \%$ gelatin, $0.05 \%$ chromium potassium sulfate). Slides were deparaffinated and incubated with $3 \%$ BSA in PBS for $45 \mathrm{~min}$ at $4^{\circ} \mathrm{C}$. The slides were then incubated with primary antibody (purified antibodies or diluted antiserum) at $4^{\circ} \mathrm{C}$ overnight. After two washes with PBS $(1 \times 30 \mathrm{~min}, 1 \times 15$ $\mathrm{min}$ ) at RT, slides were incubated again in $3 \%$ BSA in PBS for
5-10 $\mathrm{min}$ at $4^{\circ} \mathrm{C}$. Incubation with FITC-conjugated anti-rabbit IgG (Sigma) at $1: 100$ dilution in PBS was for $4-6 \mathrm{hr}$ at $4^{\circ} \mathrm{C}$ in the dark. Slides were washed $2 \times 30 \mathrm{~min}$ with $\mathrm{PBS}$ at RT, counterstained by incubation with $0.5 \mu \mathrm{g} / \mathrm{ml}$ 4,6-diamidino-2-phenylindole (DAPI) for $5 \mathrm{~min}$, and washed for $30 \mathrm{~min}$ with PBS. Slides were mounted with $\mathrm{pH} 8.5$ buffered glycerol-polyvinylalcohol mounting medium containing 25 grams/liter $\mathrm{NaI}$ as an antibleach (Böck et al. 1985). Sections were examined using epifluorescence microscopy, with appropriate filters for viewing DAPI and fluorescein fluorescence.

\section{Preparation of extracts and immunoblotting}

Nuclear protein extracts from 150 mixed-stage preneurulae embryos (majority stages 9 and 10 ) were prepared according to the method of Risley and Eckhardt (1981), except that L-1-tosyllamide-2-phenylethylchloromethylketone was not added to the buffers.

To prepare extracts of acid-soluble proteins, oocytes, eggs, or embryos were homogenized in $20 \mathrm{mM}$ Tris- $\mathrm{HCl}$ (pH 8), $150 \mathrm{~mm}$ $\mathrm{NaCl}, 0.1 \mathrm{mM}$ PMSF, $13 \mathrm{mM} \mathrm{ME}, 0.5 \mu \mathrm{g} / \mu \mathrm{l}$ of pepstatin A, 0.7 $\mu \mathrm{g} / \mu \mathrm{l}$ of leupeptin, and precipitated on ice with $70 \%$ perchloric acid to give a final concentration of $5 \%$ perchloric acid. After brief sonication, the sample was left on ice for $30 \mathrm{~min}$. The precipitate was collected by centrifugation $(10,000 \mathrm{rpm}, 30$ $\mathrm{min} /$ and the supernatant precipitated by addition of 0.2 volume of $100 \%$ trichloroacetic acid. This precipitate was collected, washed once in acidified acetone, twice with acetone, and finally dissolved in sample buffer for gel analysis.

Protein extracts were separated by SDS-polyacrylamide gel electrophoresis and immunoblotting performed by standard procedures (Towbin et al. 1979; Burnette 1981).

\section{Acknowledgments}

We wish to thank Dr. A. Moorman for his gift of Xenopus antihistone $\mathrm{Hl}$ antiserum, H. Mahr for synthesis of oligodeoxynucleotides, and N. Segil for Xenopus liver and muscle poly $(\mathrm{A})^{+}$ RNA. We thank B. Demeties for help with some of the sequencing. R.C.S. was a recipient of a postdoctoral research fellowship from the Muscular Dystrophy Association while part of this work was carried out. Some of this work was supported by National Institutes of Health grant GM 37981 to M.B.D.

\section{Note}

Sequence data described in this paper have been submitted to the EMBL/GenBank Data Libraries.

\section{References}

Bachvarova, R. and E.H. Davidson. 1966. Nuclear activation at the onset of amphibian gastrulation. J. Exp. Zool. 163: 285295.

Ballantine, J.E.M. and H.R. Woodland. 1985. Polyadenylation of histone mRNA in Xenopus oocytes and embryos. FEBS Lett. 180: $224-228$.

Böck, G., M. Hilchenbach, K. Schauenstein, and G. Wick. 1985. Photometric analysis of antifading reagents for immunofluorescence with laser and conventional illumination sources. J. Histochem. Cytochem. 33: 699-705.

Bürglin, T.R., I.W. Mattaj, D.D. Newmeyer, R. Zeller, and E.M. De Robertis. 1987. Cloning of nucleoplasmin from Xenopus laevis oocytes and analysis of its developmental expression. Genes Dev. 1: 97-107. 
Burnette, W.N. 1981. Western blotting: Electrophoretic transfer of proteins from sodium dodecyl sulfate-polyacrylamide gels to unmodified nitrocellulose and radiographic detection with antibody and radioiodinated protein A. Anal. Biochem. 112: 195-203.

Chen, E.Y. and P.H. Seeburg. 1985. Supercoil sequencing: A fast and simple method for sequencing plasmid DNA. DNA 4: $165-170$.

Church, G.M. and W. Gilbert. 1984. Genomic sequencing. Proc. Natl. Acad. Sci. 81: 1991-1995.

Cole, K.D., J.C. Kandala, and W.S. Kistler. 1986. Isolation of the gene for the testis-specific $\mathrm{Hl}$ histone variant $\mathrm{Hlt}$. J. Biol. Chem. 261: 7178-7183.

Coles, L.S., A.J. Robins, L.K. Madley, and J.R.E. Wells. 1987. Characterization of the chicken histone $\mathrm{Hl}$ gene complement: Generation of a complete set of vertebrate $\mathrm{Hl}$ protein sequences. I. Biol. Chem. 262: 9656-9663.

Destrée, O.H.J., H.A. d'Adelhart Toorop, and R. Charles. 1973. Analysis of histones from different tissues and embryos of Xenopus laevis (Daudin). II. Qualitative and quantitative aspects of nuclear histones during early stages of development. Cell Diff. 2: 229-242.

Dilworth, S.M., S.J. Black, and R.A. Laskey. 1987. Two complexes that contain histones are required for nucleosome assembly in vitro: Role of nucleoplasmin and N1 in Xenopus egg extracts. Cell 51: 1009-1018.

Dumont, J.N. 1972. Oogenesis in Xenopus laevis (Daudin): I. Stages of oocyte development in laboratory maintained animals. J. Morphol. 136: 153-180.

Dworkin, M.B. and I.B. Dawid. 1980. Construction of a cloned library of expressed embryonic gene sequences from Xenopus laevis. Dev. Biol. 76: 435-448.

Dworkin, M.B., A. Shrutkowski, and E. Dworkin-Rastl. 1985. Mobilization of specific maternal RNA species into polysomes after fertilization in Xenopus laevis. Proc. Natl. Acad. Sci. 82: 7636-7640.

Dworkin-Rastl, E., A. Shrutkowski, and M.B. Dworkin. 1984. Multiple ubiquitin mRNAs during Xenopus laevis development contain tandem repeats of the 76 amino acid coding sequence. Cell 39: 321-325.

Flenniken, A.M. and K.M. Newrock. 1987. H1 histone subtypes and subtype synthesis switches of normal and delobed embryos of Ilyanassa obsoleta. Dev. Biol. 124: 457-468.

Flynn, J.M. and H.R. Woodland. 1980. The synthesis of histone H1 during early amphibian development. Dev. Biol. 75: $222-230$.

Gantt, J.S. and J.L. Key. 1987. Molecular cloning of a pea HI histone cDNA. Eur. I. Biochem. 166: 119-125.

Gubler, U. and B.J. Hoffman. 1983. A simple and very efficient method for generating cDNA libraries. Gene 25: 263-269.

Jones, E.A. and H.R. Woodland. 1987. The development of animal cap cells in Xenopus: A measure of the start of animal cap competence to form mesoderm. Development 101: $557-563$.

Kimelman, D., M. Kirschner, and T. Scherson. 1987. The events of the midblastula transition in Xenopus are regulated by changes in the cell cycle. Cell 48: 399-407.

Koster, J.G., H.E. Kasinsky, and O.H.J. Destrée. 1979. Newly synthesized histones in chromatin of early embryos of Xenopus laevis. Cell Diff. 8: 93-104.

Kozak, M. 1987. An analysis of 5'-noncoding sequences from 699 vertebrate RNAs. Nucleic Acids Res. 15: 8125-8148.

Krieg, P.A. and D.A. Melton. 1984. Formation of the 3' end of histone mRNA by post-transcriptional processing. Nature 308: 203-206.

Kyte, J. and R.F. Doolittle. 1982. A simple method for dis- playing the hydropathic character of a protein. I. Mol. Biol. 157: $105-132$.

Laemmli, U.K. 1970. Cleavage of structural proteins during the assembly of the head of bacteriophage T4. Nature 227: 680685.

Levy, S., I. Sures, and L. Kedes. 1982. The nucleotide and amino acid coding sequence of a gene for $\mathrm{H} 1$ histone that interacts with euchromatin: The early embryonic $\mathrm{Hl}$ gene of the sea urchin Strongylocentrotus purpuratus. I. Biol. Chem. 257: 9438-9443.

Lipman, D.J. and W.R. Pearson. 1985. Rapid and sensitive protein similarity searches. Science 227: 1435-1441.

Maxam, A.M. and W. Gilbert. 1980. Sequencing end-labeled DNA with base-specific chemical cleavages. Methods Enzymol. 65: 499-560.

Melton, D.A., P.A. Krieg, M.R. Rebagliati, T. Maniatis, K. Zinn, and M.R. Green. 1984. Efficient in vitro synthesis of biologically active RNA and RNA hybridization probes from plasmids containing a bacteriophage SP6 promoter. Nucleic Acids Res. 12: 7035-7056.

Messing, J., B. Gronenborn, B. Müller-Hill, and P.H. Hofschneider. 1977. Filamentous coliphage $\mathrm{M} 13$ as a cloning vehicle: Insertion of a HindII fragment of the lac regulatory region in M13 replicative form in vitro. Proc. Natl. Acad. Sci. 74: 3642-3646.

Mezquita, J., W. Connor, R.J. Winkfein, and G.H. Dixon. 1985. An H1 histone gene from rainbow trout (Salmo gairdnerii). I. Mol. Evol. 21: 209-219.

Newport, J. and M. Kirschner. 1982. A major developmental transition in early Xenopus embryos: II. Control of the onset of transcription. Cell 30: 687-696.

Nieuwkoop, P.D. and J. Faber. 1967. Normal table of Xenopus laevis (ed. Daudin), 2nd ed. North-Holland, Amsterdam.

Okada, A., T. Shin, E. Dworkin-Rastl, M.B. Dworkin, and G. Zubay. 1985. Constancy of DNA organization of polymorphic and nonpolymorphic genes during development in Xenopus. Differentiation 29: 14-19.

Perry, M., G.H. Thomsen, and R.G. Roeder. 1985. Genomic organization and nucleotide sequence of two distinct histone gene clusters from Xenopus laevis: Identification of novel conserved upstream sequence elements. I. Mol. Biol. 185: 479-499.

Perry, M., G.H. Thomsen, and R.G. Roeder. 1986. Major transitions in histone gene expression do not occur during development in Xenopus laevis. Dev. Biol. 116: 532-538.

Risley, M.S. and R.A. Eckhardt. 1981. Hl histone variants in Xenopus laevis. Dev. Biol. 84: 79-87.

Ruderman, J.V., H.R. Woodland, and E.A. Sturgess. 1979. Modulations of histone messenger RNA during the early development of Xenopus laevis. Dev. Biol. 71: 71-82.

Rüther, U. and B. Müller-Hill. 1983. Easy identification of cDNA clones. EMBO I. 2: 1791-1794.

Towbin, H., T. Staehelin, and J. Gordon. 1979. Electrophoretic transfer of proteins from polyacrylamide gels to nitrocellulose sheets: Procedure and some applications. Proc. Natl. Acad. Sci. 76: 4350-4354.

Thiébaud, C.H. and M. Fischberg. 1977. DNA content in the genus Xenopus. Chromosoma. 59: 253-257.

Turner, P.C., T.C. Aldridge, H.R. Woodland, and R.W. Old. 1983. Nucleotide sequences of $\mathrm{Hl}$ histone genes from Xenopus laevis. A recently diverged pair of $\mathrm{H1}$ genes and an unusual Hl pseudogene. Nucleic Acids Res. 11: 4093-4107.

Van Dongen, W.M.A.M., A.F.M. Moorman, and O.H.J. Destrée. 1983. The accumulation of the maternal pool of histone H1A during oogenesis in Xenopus laevis. Cell Diff. 12: 257264. 
Vincent, J.-P., G.F. Oster, and J.C. Gerhart. 1986. Kinematics of gray crescent formation in Xenopus eggs: The displacement of subcortical cytoplasm relative to the egg surface. Dev. Biol. 113: 484-500.

Vincent, J.-P. and J.C. Gerhart. 1987. Subcortical rotation in Xenopus eggs: An early step in embryonic axis specification. Dev. Biol. 123: 526-539.

Von Holt, C., W.N. Strickland, W.F. Brandt, and M.S. Strickland. 1979. More histone structures. FEBS Lett. 100: 201218.

Woodland, H.R., J.M. Flynn, and A.J. Wyllie. 1979. Utilization of stored mRNA in Xenopus embryos and its replacement by newly synthesized transcripts: Histone $\mathrm{H} 1$ synthesis using interspecies hybrids. Cell 18: 165-171. 


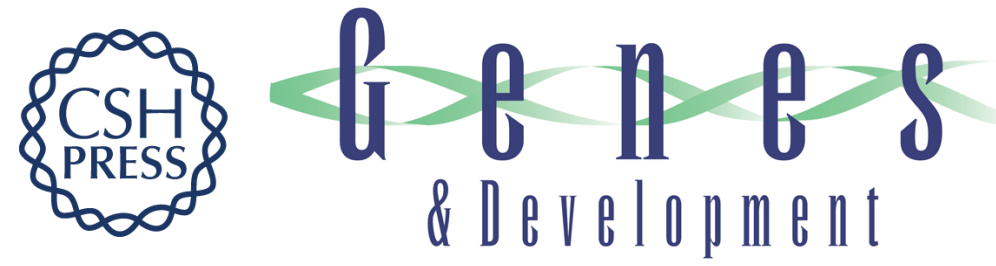

\section{Expression of a histone H1-like protein is restricted to early Xenopus development.}

R C Smith, E Dworkin-Rastl and M B Dworkin

Genes Dev. 1988, 2:

Access the most recent version at doi:10.1101/gad.2.10.1284

References This article cites 47 articles, 10 of which can be accessed free at:

http://genesdev.cshlp.org/content/2/10/1284.full.html\#ref-list-1

License

Email Alerting

Service

Receive free email alerts when new articles cite this article - sign up in the box at the top right corner of the article or click here.

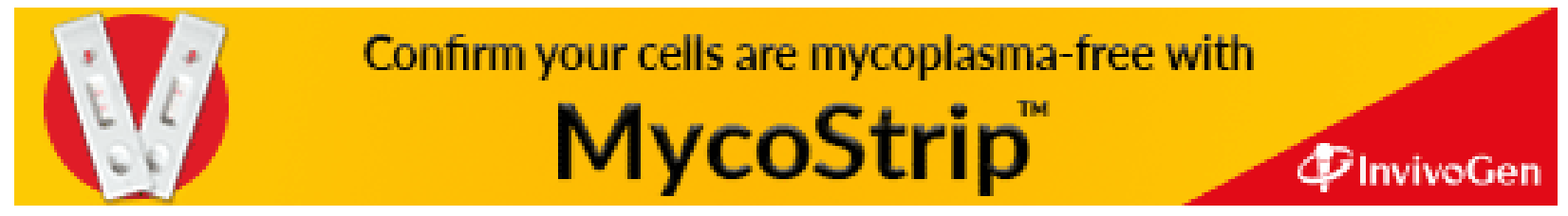

